\title{
Polymorphisms of Gene Cassette Promoters of the Class 1 Integron in Clinical Proteus Isolates
}

OPEN ACCESS

Edited by:

José Luis Capelo,

Universidade Nova de Lisboa,

Portugal

Reviewed by:

Miklos Fuzi,

Semmelweis University, Hungary

Benjamin Andrew Evans,

University of East Anglia,

United Kingdom

*Correspondence:

Quhao Wei

lab_wqh@126.com

Weiwei Liu

huashanvivian@126.com

Specialty section:

This article was submitted to

Antimicrobials, Resistance

and Chemotherapy

a section of the journal

Frontiers in Microbiology

Received: 02 November 2018

Accepted: 27 March 2019

Published: 24 April 2019

Citation:

Xiao L, Wang X, Kong N, Cao M,

Zhang L, Wei Q and Liu W (2019)

Polymorphisms of Gene Cassette Promoters of the Class 1 Integron

in Clinical Proteus Isolates.

Front. Microbiol. 10:790.

doi: 10.3389/fmicb.2019.00790

\begin{abstract}
Linlin Xiao ${ }^{1,2,3}$, Xiaotong Wang ${ }^{4}$, Nana Kong $^{4}$, Mei Cao ${ }^{4}$, Long Zhang ${ }^{4}$, Quhao Wei ${ }^{1,2,4,5 *}$ and Weiwei Liu ${ }^{3,6,7 *}$

'Shanghai University of Medicine \& Health Sciences Affiliated Sixth People's Hospital South Campus, Shanghai, China, 2 Department of Laboratory Medicine, Affiliated Sixth People's Hospital South Campus, Shanghai Jiaotong University, Shanghai, China, ${ }^{3}$ Department of Laboratory Medicine, Shanghai Tenth People's Hospital, Tongji University, Shanghai, China, ${ }^{4}$ Anhui University of Science and Technology, Anhui, China, ${ }^{5}$ Centre of Laboratory Medicine, Zhejiang Provincial People's Hospital, Hangzhou, China, ${ }^{6}$ Department of Laboratory Medicine, Shanghai Skin Disease Hospital, Tongji University, Shanghai, China, ' Department of Laboratory Medicine, Shanghai First People's Hospital, Shanghai Jiaotong University, Shanghai, China
\end{abstract}

Objective: To describe the polymorphisms of gene cassette promoters of the class 1 integron in clinical Proteus isolates and their relationship with antibiotic resistance.

Methods: Polymorphisms of the gene cassette promoter in 153 strains of Proteus were analyzed by PCR and nucleotide sequencing. Variable regions of atypical class 1 integrons were detected by inverse PCR and nucleotide sequencing. Enterobacterial repetitive intergenic consensus (ERIC)-PCR was used to analyze the phylogenetic relationships of class 1 integron-positive clinical Proteus isolates. Representative beta-lactamase genes (b/a), including

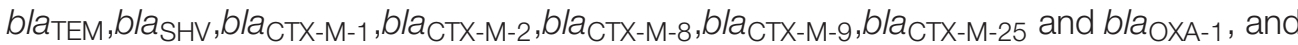
plasmid-mediated quinolone resistance (PMQR) genes including $q n r A$, qnrB, qnrC, $q n r D$, qnrS, oqxA, oqxB, qepA, and aac $\left(6^{\prime}\right)-l b$ were also screened using PCR and sequence analysis.

Results: Fifteen different gene cassette arrays and 20 different gene cassettes were detected in integron-positive strains. Of them, aadB-aadA2 (37/96) was the most common gene cassette array. Two of these gene cassette arrays (est $X$-psp-aadA2cmIA1, estX-psp-aadA2-cmIA1-aadA1a-qacl-tnpA-sul3) have not previously been reported. Three different $\mathrm{Pc}-\mathrm{P} 2$ variants (PcS, $\mathrm{PcW}_{\mathrm{TGN}-10}, \mathrm{PcH} 1$ ) were detected among the 96 Proteus strains, with $\mathrm{PcH} 1$ being the most common (49/96). Strains carrying the promoters PcS or PcW $\mathrm{TGN}_{-10}$ were more resistant to sulfamethoxazole, gentamicin and tobramycin than those carrying $\mathrm{PcH} 1$. Strains with weak promoter $(\mathrm{PcH} 1)$ harbored significantly more intra- and extra-integron antibiotic resistance genes than isolates with strong promoter $\left(\mathrm{PcW}_{\mathrm{TGN}-10}\right)$. Further, among 153 isolates, representative betalactamase genes were detected in 70 isolates (blaTEM-1, 54; blaOXA-1, 40; bla

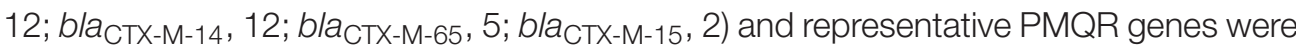
detected in 87 isolates (qnrA, 6; qnrB, 3; qnrC, 5; qnrD, 46; qnrS, 5; oqxA, 7; aac(6')-Ib, 13; $\left.\operatorname{aac}\left(6^{\prime}\right)-I b-c r, 32\right)$.

Conclusion: To the best of our knowledge, this study provides the first evidence for polymorphisms of the class 1 integron variable promoter in clinical Proteus isolates, 
which generally contain relatively strong promoters. Resistance genotypes showed a higher coincidence rate with the drug-resistant phenotype in strong-promotercontaining strains, resulting in an ability to confer strong resistance to antibiotics among host bacteria and a relatively limited ability to capture gene cassettes. Moreover, strains with relatively weak integron promoters can "afford" a heavier "extra-integron antibiotic resistance gene load". Furthermore, the gene cassettes est $X$, psp and the gene cassette arrays estX-psp-aadA2-cmIA1, estX-psp-aadA2-cmIA1-aadA1a-qacl-tnpA-sul3 have been confirmed for the first time in clinical Proteus isolates. Beta-lactamase genes and PMQR were investigated, and bla $\mathrm{TEM}_{\mathrm{E}-1}$ and blaOXA-1 were the most common, with qnrD and aac $\left(6^{\prime}\right)-\mathrm{lb}$ - $\mathrm{Cr}$ also being dominant.

Keywords: integron, gene cassettes, promoter, beta-lactamase genes, PMQR

\section{INTRODUCTION}

P. mirabilis is an important causative pathogen of various community and healthcare-associated infections, such as wound infections, primary bacteremia, pneumonia and urinary tract infections, particularly among patients with anatomical or functional urinary tract abnormalities or indwelling urinary catheters (Ahn et al., 2017). The incidence of antimicrobial resistance to $P$. mirabilis has increased, and the prevalence of $P$. mirabilis strains producing extended-spectrum $\beta$-lactamases (ESBLs), AmpC $\beta$-lactamases, carbapenemases or integrons has increased worldwide (Rzeczkowska et al., 2012). However, the impact of these elements in P. mirabilis infections on antimicrobial resistance is unclear. The extensive use of antibiotics leads to increased selection pressures, resulting in the emergence of antibiotic-resistant bacterial strains. Integration of exogenous antibiotic resistance genes (Guerin et al., 2009; Grieb et al., 2017) via site-specific recombination is an important pathway in the development of clinical antibiotic-resistant strains. Class 1 integrons are highly mobile and repetitive bacterial elements that integrate foreign gene cassettes and promote the expression of genes in the gene cassettes (Frumerie et al., 2010; Loot et al., 2012; Nivina et al., 2016). In addition, class 1 integrons can be integrated into chromosomes, plasmids, or transposons, carrying resistance genes with them, therefore play an important role in the formation and dissemination of drug-resistant bacterial strains (Collis et al., 2002; Ghazi et al., 2015; Makena et al., 2015; Moyo et al., 2015). The classical structure of class 1 integrons includes an integrase gene intI1, a recombination site attI1, an integrase gene transcription promoter, a lexA-binding site that regulates integrase gene expression, and a variable region gene cassette promoter (Collis et al., 1998, 2002; Collis and Hall, 2004; Demarre et al., 2007).

Gene cassettes in the class 1 integron usually do not include their own promoter, and their transcription depends on the common promoters Pc and P2 (Subedi et al., 2018). Several kinds of Pc variants have been defined in class 1 integrons based on their -35 and -10 hexamer sequences, and the relative strengths of these Pc variant promoters have been verified experimentally. In addition to the Pc promoter, some class 1 integrons also contain a second co-promoter P2, located about $90 \mathrm{bp}$ downstream of Pc, which inserts three $G$ residues between the -35 and -10 hexamer sequences, thus increasing the number of spaced bases to $17 \mathrm{bp}$, representing an active P2 promoter (Lévesque et al., 1994; Brizio et al., 2006; Papagiannitsis et al., 2009; Vinue et al., 2011; Moura et al., 2012). A recent study reported a new $\mathrm{P} 2$ promoter variant, $\mathrm{P} 2 \mathrm{~m} 3$, with a similar strength to the $\mathrm{PcW}_{\mathrm{TGN}-10}$ variant (Lin et al., 2017). Jove et al. (2010) described variants of various types of Pc promoters, and noted that promoter polymorphisms could result in changes in the amino acid species in the IntIl sequence, with the magnitude of the change in the excision activity of the mutant integrase being greater than the magnitude of the change in its integration activity. In addition, given identical Pc promoters, the integration efficiency is significantly reduced if the $\mathrm{P} 2$ promoter is located before the attI1 site (Guerin et al., 2011). Guerin et al. (2011) carried out a detailed study of the transcriptional interference relationship between the intI1 promoter PintI1 and the Pc or Pc-P2 combination and showed that higher gene cassette transcription levels inhibited expression of the integrase in class 1 integrons. The Pc and P2 co-promoter of class 1 integrons therefore not only play an important role in driving the transcription of downstream gene cassettes or gene cassette arrays, but also have a close relationship with the resection and integration phenomena that occur during the capture of exogenous gene cassettes. However, no promoter-related studies of class 1 integrons in clinical isolates of Proteus have yet been reported. In this study, we investigated the polymorphisms of the co-promoter of class 1 integrons and their association with the antibiotic resistance phenotype in clinical isolates of Proteus.

\section{MATERIALS AND METHODS}

\section{Bacterial Strains and Susceptibility Testing}

We previously obtained 153 strains of Proteus from patient samples from Zhejiang Province (Wei et al., 2014). These clinical isolates included $140 \mathrm{P}$. mirabilis isolates, 12 Proteus vulgaris isolates and 1 Proteus penneri isolate. Among these, 96 class 1 integron positive strains were studied further. Escherichia coli ATCC25922 and E. coli DH5a were also maintained in our laboratory. Antibiotic susceptibility was determined by disk diffusion and broth dilution. E. coli 
ATCC25922 was used as a control strain. The tested antibiotics included: amikacin, gentamicin, tobramycin, sulfamethoxazole, chloramphenicol, Meropenem, Imipenem, Ciprofloxacin, Levofloxacin, Aztreonam, Cefepime, Ceftriaxone, Ceftazidime, Cefotetan, and Cefazolin. The results were interpreted in accordance with the guidelines of the Clinical and Laboratory Standards Institute.

\section{Structural Analysis of Atypical Class 1 Integrons}

Bacterial DNA preparation and class 1 integron analysis were conducted and reported as previously (Wei et al., 2014). Variable regions of atypical class 1 integrons that could not be amplified conventionally were detected by inverse PCR analysis of genomic DNA using the primer pairs INTRR and INTRF, followed by verification by electrophoresis and sequencing (Table 1 and Figure 1). For $a a c\left(6^{\prime}\right)-I b$ gene positive isolates, the variable regions were also amplified through overlap PCR using the primer pairs intF and aacR, aacF and 3CS. PCR products were analyzed by sequencing. All sequencing results were aligned using the BLAST program ${ }^{1}$.

\section{Characterization of Pc and P2 Promoters of Class 1 Integrons}

For typical class 1 integrons, the type of promoter upstream of the variable region was identified by direct sequencing. For atypical class 1 integrons, Pc and P2 promoters were identified by sequencing the PCR products amplified using the primer intF combined with specific primers for the downstream gene cassettes. For strains that cannot be successfully amplified using intF and specific primers for the downstream gene cassette, the class 1 integron-mixed common promoter was amplified only by intF and P2R2 primer pairs (some strains may contain multiple integrons). All of them were sequenced using the primer intF after electrophoresis validation, and the variable region promoter type was interpreted based on the sequence.

\section{Polymerase Chain Reaction Detection and Sequencing of \\ Beta-Lactamase Genes}

To determine the genotype of beta-lactamase, we performed PCR amplification with bla $a_{\mathrm{TEM}}, b l a_{\mathrm{SHV}}, b l a_{\mathrm{CTX}-\mathrm{M}-1}, b l a_{\mathrm{CTX}-\mathrm{M}-2}$, $b l a_{\text {CTX-M-8 }}, b l a_{\text {CTX-M-9 }}, b l a_{\text {CTX-M-25, }}$, and bla $a_{\text {OXA-1. }}$. Specific primers that were designed to detect beta-lactamase gene markers (Table 1) were used to screen for beta-lactamase antibiotic resistance gene in bacterial isolate template DNA. The total volume of the PCR mixture was $20 \mu \mathrm{l}$, containing $1 \mu \mathrm{l}$ of genomic DNA template, $0.4 \mu \mathrm{l}$ of each primer (10 pmol), $10 \mu \mathrm{l}$ of Premix-rTaq PCR solution (TaKaRa, Japan), and $7 \mu$ l of distilled water. PCR was carried out using an ABI Veriti Thermal Cycler (Applied Biosystems, Singapore). The template was initially denatured at $94^{\circ} \mathrm{C}$ for $4 \mathrm{~min}$, followed by 35 cycles of $94^{\circ} \mathrm{C}$ for $40 \mathrm{~s}, 55^{\circ} \mathrm{C}$ for $40 \mathrm{~s}$, and $72^{\circ} \mathrm{C}$ for $40 \mathrm{~s}$, with a final extension at $72^{\circ} \mathrm{C}$ for $5 \mathrm{~min}$. PCR products were verified by electrophoresis

${ }^{1}$ http://www.ncbi.nlm.nih.gov/BLAST
TABLE 1 | Primers used for PCR amplification.

\begin{tabular}{|c|c|c|}
\hline Primer & Primer sequence $\left(5^{\prime}-3^{\prime}\right)$ & References \\
\hline intF & CCAAGCTCTCGGGTAACATC & Wei et al., 2011 \\
\hline P2R2 & CCCGAGGCATAGACTGTA & Sunde, 2005 \\
\hline ERIC2 & AAGTAAGTGACTGGGGTGAGCG & Tsai et al., 2018 \\
\hline $3 C S$ & AAGCAGACTTGACCTGA & Sunde, 2005 \\
\hline INTRF & TCGGCCATTCCGACGTCTCTAC & Sunde, 2005 \\
\hline INTRR & TGCAAGTAGCGTATGCGCTC & Sunde, 2005 \\
\hline CMLF & AAACGCGCTTGGTACGACAGC & This study \\
\hline CMLR & АТTACTTTCCTCGCGACCTGC & This study \\
\hline AADA2F & CGATGAGCGAAATGTAGTG & This study \\
\hline AADA2R & AAGACGGGCTGATACTGG & This study \\
\hline ESTXF & AGGTCAGGCTCCATATTCC & This study \\
\hline ESTXR & TGAATGTTGTCAGGATATTC & This study \\
\hline QACF & TTGGTGAGGTCGTCGCAAC & This study \\
\hline QACR & TGCGCTGACCTTGGATAGC & This study \\
\hline SUL3F & GAGCAAGATIITGGAATCG & This study \\
\hline PSPF & TCGATGGCACAATTACCAC & This study \\
\hline QD14R1 & CCTGAGCGGGTAACGAC & This study \\
\hline IS26R & TTGCGTAGTGCACGCATCACC & This study \\
\hline CMLF2 & TAGGTTTGGGCATGATC & This study \\
\hline TEMF & TCGGGGAAATGTGCG & Velasova et al., 2019 \\
\hline TEMR & TGCTTAATCAGTGAGGCACC & Velasova et al., 2019 \\
\hline SHVF & GCCTIATCGGCCTTCACTCAAG & Velasova et al., 2019 \\
\hline SHVR & TTAGCGTTGCCAGTGCTCGATCA & Velasova et al., 2019 \\
\hline CTX-M-1F & CAGAGATITTGCCGTCTAAG & Velasova et al., 2019 \\
\hline CTX-M-1R & GGCCCATGGTTAAAAAATCACTGC & Velasova et al., 2019 \\
\hline CTX-M-2F & CTCAGAGCATTCGCCGCTCA & Velasova et al., 2019 \\
\hline CTX-M-2R & CCGCCGCAGCCAGAATATCC & Velasova et al., 2019 \\
\hline CTX-M-8F & ACTTCAGCCACACGGATTCA & Velasova et al., 2019 \\
\hline CTX-M-8R & CGAGTACGTCACGACGACTT & Velasova et al., 2019 \\
\hline CTX-M-9F & GTTACAGCCCTTCGGCGATGATTC & Velasova et al., 2019 \\
\hline CTX-M-9R & GCGCATGGTGACAAAGAGAGTGCAA & Velasova et al., 2019 \\
\hline CTX-M-25F & GCACGATGACATTCGGG & Velasova et al., 2019 \\
\hline CTX-M-25R & AACCCACGATGTGGGTAGC & Velasova et al., 2019 \\
\hline OXA-1-F & GGCACCAGATTCAACTTTCAAG & Che et al., 2014 \\
\hline OXA-1-R & GACCCCAAGTTTCCTGTAAGTG & Che et al., 2014 \\
\hline qnrAF & AGAGGATTTCTCACGCCAGG & Kim et al., 2016 \\
\hline qnrAR & GCAGCACTATKACTCCCAAGG & Kim et al., 2016 \\
\hline qnrBF & GGMATHGAAATTCGCCACTG & Kim et al., 2016 \\
\hline qnrBR & TाTGCYGYYCGCCAGTCGAA & Kim et al., 2016 \\
\hline qnrCF & GGGTTGTACATTTATTGAATC & Kim et al., 2016 \\
\hline qnrCR & TCCACTTTACGAGGTTCT & Kim et al., 2016 \\
\hline qnrDF & CGAGATCAATTTACGGGGAATA & Kim et al., 2016 \\
\hline qnrDR & AACAAGCTGAAGCGCCTG & Kim et al., 2016 \\
\hline qnrSF & GCAAGTTCATTGAACAGGCT & Kim et al., 2016 \\
\hline qnrSR & TCTAAACCGTCGAGTTCGGCG & Kim et al., 2016 \\
\hline oqxAF & GACAGCGTCGCACAGAATG & Wong et al., 2014 \\
\hline oqxAR & GGAGACGAGGTTGGTATGGA & Wong et al., 2014 \\
\hline oqxBF & CGAAGAAAGACCTCCCTACCC & Kim et al., 2016 \\
\hline oqxBR & CGCCGCCAATGAGATACA & Kim et al., 2016 \\
\hline qepAF & CTGCAGGTACTGCGTCATG & Wong et al., 2014 \\
\hline qepAR & CGTGTTGCTGGAGTTCTTC & Wong et al., 2014 \\
\hline aacF & ATCTCATATCGTCGAGTGG & This study \\
\hline aacR & TGCGTGTTCGCTCGAATGC & This study \\
\hline
\end{tabular}




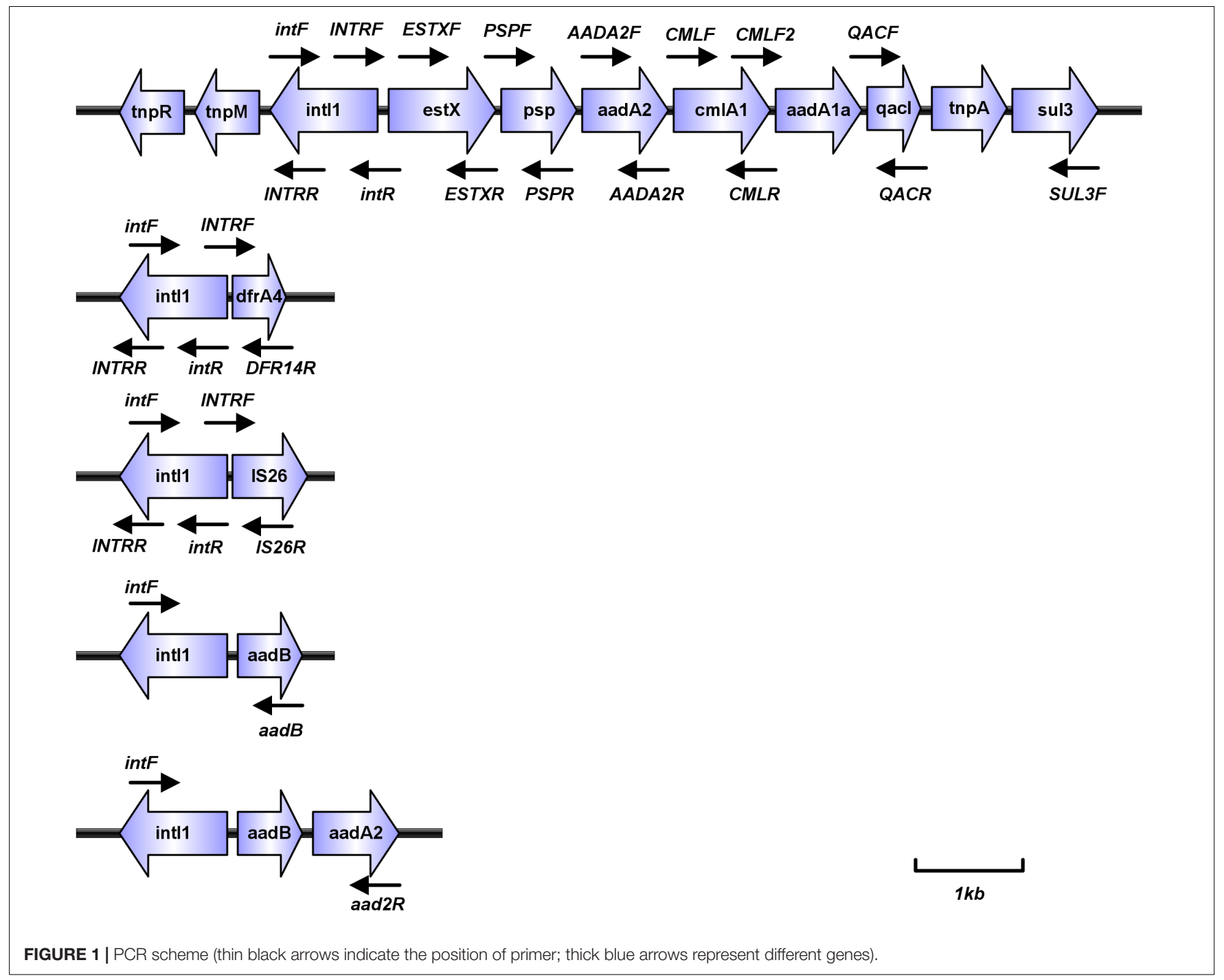

and sequencing (Table 1). All sequencing results were aligned using the BLAST program.

\section{Multiplex PCR Detection of Plasmid-Mediated Quinolone Resistance Genes}

To determine the genotype of plasmid-mediated fluoroquinolone resistance genes, we performed PCR amplification with the $q n r A$ (length = 619 bp), qnrB (length = $264 \mathrm{bp}), q n r C($ length $=447 \mathrm{bp})$, qnrD (length $=582 \mathrm{bp}$ ), qnrS (length = $428 \mathrm{bp}$ ), oqxA $($ length $=339 \mathrm{bp}), o q x B($ length $=240 \mathrm{bp})$, qepA $($ length $=403 \mathrm{bp})$, and $a a c\left(6^{\prime}\right)-I b$, qnrA/qnrB/qnrC as the first multiplex PCR amplification system, and $q n r D / q n r S / o q \times A / o q \times B$ as the second multiplex PCR amplification system. qepA and $a a c\left(6^{\prime}\right)-I b$ were separately amplified. Specific primers which were designed for fluoroquinolone resistance maker (Table 1) were used to screen for antibiotic resistance genes in bacterial isolate template DNA. PCR amplification components and cycling conditions were identical to those used for the detection of BLA antibiotic resistance genes described above, followed by verification by electrophoresis. All $a a c\left(6^{\prime}\right)-I b$ positive products were then sequenced (Table 1). All sequencing results were aligned using the Vector NTI Advance 11 (Invitrogen, United States).

\section{Determination of Phylogenetic Groups of Proteus}

We analyzed the phylogenetic population of the 96 integronpositive Proteus strains based on the Enterobacterial repetitive intergenic consensus (ERIC)-PCR method (Wilson and Sharp, 2006). Phylogenetic groups of Proteus strains were determined according to the electrophoresis patterns of the PCR product by NTSYSpc 2.1e software (clustering program).

\section{Statistical Analysis}

All statistical analyses were performed using SPSS software, version 22.0. To compare the two groups, the Student's $t$-test or Mann-Whitney $u$-test, depending on the validity of the normality assumption, was used for continuous variables. The chi-squared 
test or Fisher's exact test was used to assess categorical variables. Values of $p<0.01$ were considered to indicate significance.

\section{RESULTS}

\section{Antimicrobial Susceptibility}

In this study, 153 strains of Proteus were isolated mainly from patients in the Internal Medicine surgery ward [53.6\% $(82 / 153)]$, the ICU [37.3\% (57/153)] and the Outpatient clinic [9.1\% (14/153)]. The cohort of 153 patients had a mean age of 67.2 years, which a range of 5-91. $104(68.0 \%)$ patients were over 60 years old. The main sources of Proteus were from genital secretions [17.6\% (27/153)], urine [41.2\% (63/153)], sputa $[32.7 \%(50 / 153)]$, hydrothorax and ascite $[5.9 \%(9 / 153)]$, and blood [2.6\% (4/153)].

The in vitro antimicrobial susceptibilities of the Proteus isolates showed that most isolates were susceptible to Imipenem (60\%), Meropenem (55.6\%), Ciprofloxacin (40.5\%), Levofloxacin (52.3\%), Cefepime (63.4\%), Ceftriaxone (58.8\%), Ceftazidime (58.2\%), Cefazolin (41.8\%), Aztreonam (79.1\%), Amikacin (81.7\%), Gentamicin (47.1\%), Tobramycin (45.6\%), Sulfamethoxazole (43.1\%), and Chloramphenicol (61.4\%). Moreover, all of the isolates were susceptible to Piperacillin/Tazobactam and Cefotetan.

\section{Characterization of Gene Cassettes and Arrays}

Of 96 class 1 integrin-positive strains, 70 variable regions of typical integrons were previously detected in Proteus strains (Wei et al., 2013). Variable regions in 26 atypical class 1 integrons were analyzed using inverse PCR. For aac $\left(6^{\prime}\right)-I b$ gene positive isolates, the variable regions were amplified through overlap PCR. A total of 15 different types of variable region gene cassette arrays and 20 different gene cassettes were detected. These gene cassette arrays were divided into types $\mathrm{A}-\mathrm{K}$, of which type $\mathrm{K}$ included $\mathrm{K} 1$ and $\mathrm{K} 2$ (Figure 2). The most common antibiotic resistance gene cassettes were aadA2 (72/96), aadB (38/96), and aadA1a (22/96), all of which conferred resistance to aminoglycoside antibiotics. Five trimethoprim-resistance gene cassettes [dfrA17 (17/96), dfrA12 (6/96), dfrA32 (4/96), dfrA1 (2/96), dfrA14 (1/96)] conferred resistance to trimethoprim antibiotics; in addition, we also found $a a c\left(6^{\prime}\right)-I b$ gene cassettes (16/96) in the integron variable region, and a chloramphenicol-resistance gene cassette cmlA1 (2/96). The gene cassette arrays were partly detected in strain NO.47685 (IS26) and strain NO.50772 (dfrA14), but variable regions were not detected in strain NO.45016 (Table 2). The most common gene cassette arrays were aadB-aadA2, estX-psp-aadA2-cmlA1aadA1a-qacI-tnpA-sul3, and $d$ frA17-aadA5, which were detected in 37,22 , and 17 isolates, respectively.

\section{Class 1 Integron Promoter Variants}

We analyzed the promoters of class 1 integrons. All bacterial strains are shown in Table 2 . Three common types of promoters were detected among the 96 clinical isolates of integron-positive Proteus strains. The most common promoter was $\mathrm{PcH} 1$, which was a relatively weak promoter occurring in 51\% (49/96) of class 1 integron-positive strains (Wei et al., 2011), while PcS was the second most prevalent promoter, present in $41.6 \%(40 / 96)$, and the PcW $\mathrm{TGN}_{\mathrm{TGN}}$ was detected in only $7.3 \%$ (7/96) of class 1 integron-positive strains. An inactive P2 promoter unable to drive the expression of downstream gene cassettes was detected in all class 1 integron-positive strains.

Regarding the relationship between gene cassettes or gene cassette arrays and specific common promoters, $\mathrm{PcH} 1$ could drive the expression of estX-psp-aadA2-cmlA1-aadA1a-qacI-tnpA-sul3, dfrA17-aadA5, dfrA32-ereA-aadA2, and estX-psp-aadA2-cmlA1 gene cassette arrays, $\mathrm{PcS}$ could drive $\operatorname{aadB}-\operatorname{aad} A 2$, $\operatorname{aad} B$, and aadA2 gene cassette arrays, and $\mathrm{PcW}_{\mathrm{TGN}-10}$ could drive the expression of $d f r A 1$-orfC and aacA4-cmlA1 gene cassette arrays. In addition, all three types of promoters (PcS, PcH1, and $\mathrm{PcW}_{\mathrm{TGN}-10}$ ) could drive the expression of the gene cassette array dfrA12-orfF-aadA2.

\section{Associations Between Common Promoter Variants and Phylogenetic Groups of Proteus}

We analyzed the phylogenetic relationships between clinical isolates of Proteus. We divided the 96 clinical isolates of class 1 integron-positive Proteus into seven groups (a1, a2, b, c1, c2, d1, and $\mathrm{d} 2$ ) according to the ERIC-PCR results. Among these, two strains belonged to group a1 [PcW $\left.\mathrm{PGN}_{\mathrm{T}-10}(2 / 2)\right], 39$ to group a2 [PcS (39/39)], 24 to group b [PcH1 (20/24), PcW TGN-10 (3/24), $\mathrm{PcS}(1 / 24)]$, six to group c1 [PcH1 (4/6), $\left.\mathrm{PcW}_{\mathrm{TGN}-10}(2 / 6)\right]$, one to group c2 ( $\mathrm{PcH} 1), 23$ to group d1 [PcH1 (23/23)], and one to group $\mathrm{d} 2(\mathrm{PcH} 1)$ (Figure 3). The a1, a2, and d1 groups each included a single promoter type. The c2 (strain NO.45016) and $\mathrm{d} 2$ groups (strain NO.47685) each included only one strain, among which the integron variable region of 45016 could not be detected and the integron variable region of 47685 was an insertion sequence (IS26), which was different from that of other strains.

\section{Relationships Between Proteus Pc and Pc-P2 Promoters and Resistance Phenotype}

We tested the 96 class 1 integron-positive Proteus strains for antibiotic susceptibility, to clarify the relationship between the integron variable region promoter and the antibioticresistance phenotype in clinical isolates. Integron-positive strains containing relatively strong promoters had higher resistance rates to amikacin, gentamicin, and tobramycin, but low resistance to chloramphenicol (Table 3). There was no significant difference in sulfamethoxazole and chloramphenicol resistance rates between strains with relatively strong and weak promoters. However, strains with strong promoters still had higher $\mathrm{MIC}_{50}$ values for chloramphenicol than strains with weak promoters. We performed a more detailed analysis of the promoters and antibiotic-resistance phenotypes in the seven strains of bacteria with strong promoters (PcW $\left.\mathrm{TGN}_{-10}\right)$ and showed that resistance phenotype was associated with the presence of a strong promoter ( $\left.\mathrm{PcW}_{\mathrm{TGN}-10}\right)$, while 


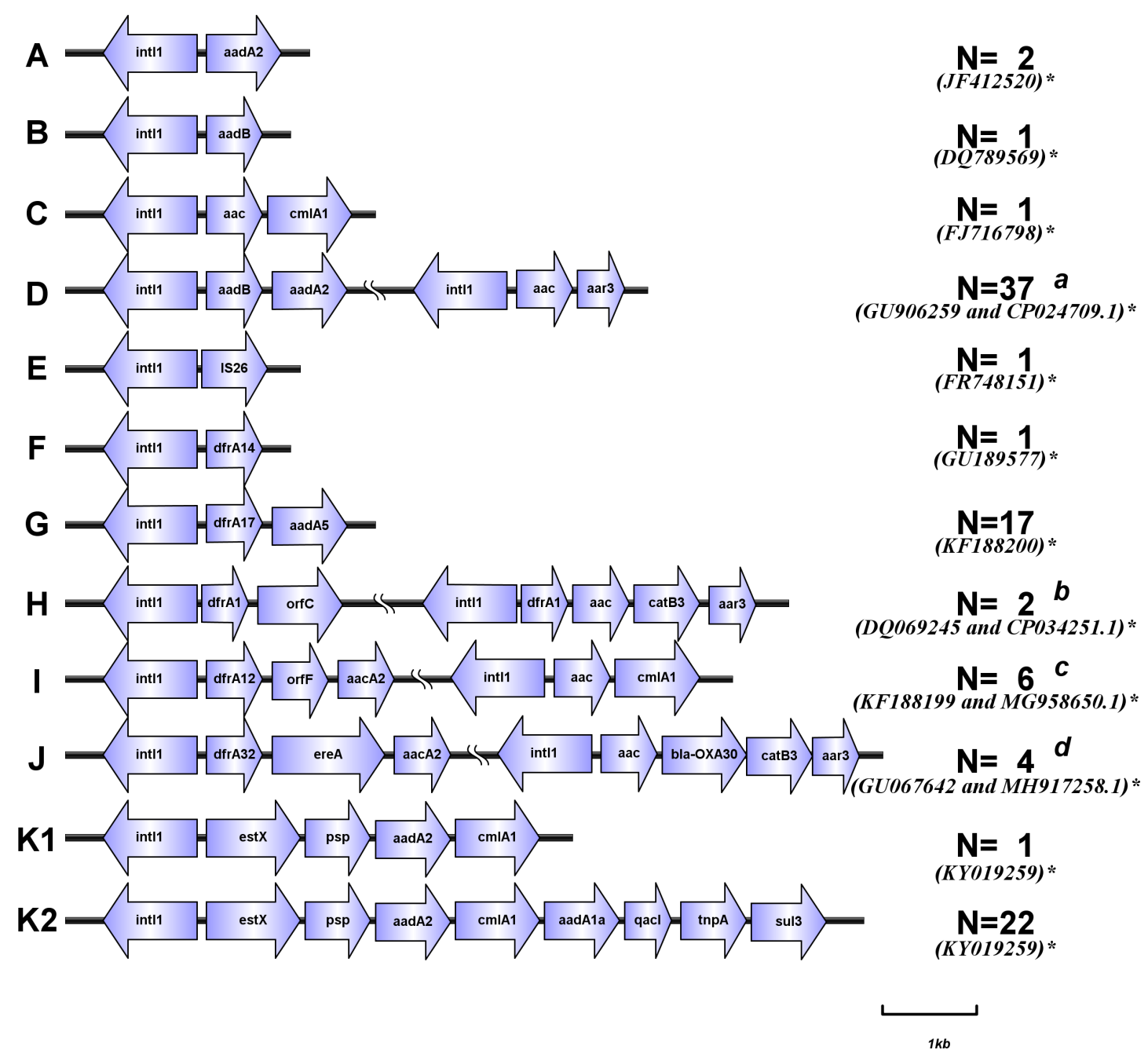

FIGURE 2 | Schematic representation of different types of gene cassette arrays (aac equal to aac $\left(6^{\prime}\right)$-Ib or aac $\left(6^{\prime}\right)$-Ib-cr). *Accession numbers in Genbank. ${ }^{*}$ Among the 37 isolates, 25 of the integron variable regions were aadB-aadA2, and the other 12 were aadB-aadA2 and aac $\left(6^{\prime}\right)$-Ib-aar3. ${ }^{b} A m o n g$ the 2 isolates, 1 of the integron variable regions were $d f r A 1$-orfC, and the other 1 was $d f r A 1-o r f C$ and $d f r A 1-a a c\left(6^{\prime}\right)-l b$-catB3-aar3. ${ }^{c} A m o n g$ the 6 isolates, 5 of the integron variable regions were dfrA12-orfF-aacA2, and the other 1 was $d f r A 12$-orfF-aacA2 and aac $\left(6^{\prime}\right)-I b-c m I A 1$, the second array (aac $\left(6^{\prime}\right)$ - $\left.I b-c m I A 1\right)$ is the same as $C\left(\right.$ aac $\left(6^{\prime}\right)-I b$ -cmIA1). ${ }^{d}$ Among the 4 isolates, 3 of the integron variable regions were $d f r A 32-e r e A$-aacA2, and the other 1 was $d f r A 32-e r e A-a a c A 2$ and aac( $\left.6^{\prime}\right)$-Ib -bla-oXA-1-catB3-aar3. (Sequences of PCR products were analyzed with BLAST to identify target homologous sequences and their GenBank accession numbers. https://blast.ncbi.nlm.nih.gov/Blast.cgi).

this phenomenon was not observed in other promoter types (Figure 4).

\section{Genotypes of Beta-Lactamase Genes}

Among the beta-lactamase producing strains, we found 55 isolates that were positive for bla $a_{\mathrm{TEM}}, 15$ isolates positive for the bla $a_{\mathrm{CTX}-\mathrm{M}-1}$ group, 17 isolates positive for the bla $a_{\mathrm{CTX}-\mathrm{M}-9}$ group and 40 isolates positive for the bla $a_{\mathrm{OXA}-1}$ group. Using nucleotide sequence analysis, we found that 55 bla $a_{\text {TEM }}$ positive isolates carried $b l a_{\mathrm{TEM}-1}$. Of 15 bla $_{\mathrm{CTX}-\mathrm{M}-1}$ group positive isolates, 12 had bla $a_{\mathrm{CTX}-\mathrm{M}-3}$ and 3 carried bla $a_{\mathrm{CTX}-\mathrm{M}-15}$. Meanwhile, of 17

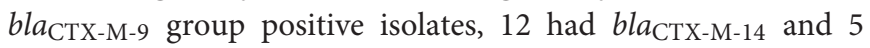
had bla $a_{\text {CTX-M-65. All } 40 \text { bla }}$ OXA-1 group positive isolates were found to carry bla OXA-1. Meanwhile, all 153 isolates were negative for bla $a_{\mathrm{SHV}}, b l a_{\mathrm{CTX}-\mathrm{M}-2}$ group, bla $a_{\mathrm{CTX}-\mathrm{M}-8}$ group and bla $a_{\mathrm{CTX}-\mathrm{M}-25}$ group. Statistical analysis of the drug-sensitive phenotypes of the beta-lactamase positive and negative-positive groups revealed that the beta-lactamase positive group was significantly less sensitive to Ceftriaxone ( $35.7 \%$ vs. $77.1 \%, p<0.01$ ), Ceftazidime (31.4\% vs. $80.7 \%, p<0.01)$, Cefazolin (38.6\% vs. $84.3 \%, p<0.01$ ), Imipenem (37.1\% vs. $79.51 \%, p<0.01)$, and Meropenem $(35.71 \%$ vs. $72.3 \%, p<0.01)$ than the beta-lactamase negative group (Table 4).

\section{Plasmid-Mediated Quinolone Resistance Gene}

Among 153 Proteus samples, we found 6 isolates positive for $q n r A, 3$ isolates positive for $q n r B, 5$ isolates positive for 
TABLE 2 | Gene cassette arrays and their common promoters in 96(class 1 integrons)Proteus strains.

\begin{tabular}{|c|c|c|c|c|}
\hline \multirow[t]{2}{*}{ Gene cassette array } & \multicolumn{3}{|c|}{ Type promoter } & \multirow[t]{2}{*}{ Total } \\
\hline & $\mathrm{PcH} 1$ & $\mathrm{PcW}_{\mathrm{TGN}-10}$ & PcS & \\
\hline aadA2* & & & 2 & 2 \\
\hline aadB* & & 1 & & 1 \\
\hline $\operatorname{aac}\left(6^{\prime}\right)-I b-c m \mid A 1^{*}$ & & 1 & & 1 \\
\hline aadB-aadA2* & & & 37 & 37 \\
\hline $\operatorname{IS} 26^{a}$ & 1 & & & 1 \\
\hline dfrA14a & 1 & & & 1 \\
\hline dfrA17-aadA5* & 17 & & & 17 \\
\hline dfrA1-orfC* & & 2 & & 2 \\
\hline dfrA12-orfF-aadA2* & 2 & 3 & 1 & 6 \\
\hline dfrA32-ereA-aadA2* & 4 & & & 4 \\
\hline estX-psp-aadA2-cm/A1 & 1 & & & 1 \\
\hline $\begin{array}{l}\text { estX-psp-aadA2- } \\
\text { cmlA1-aadA1a-qacl- } \\
\text { tnpA-sul3 }\end{array}$ & 22 & & & 22 \\
\hline Unknown ${ }^{b}$ & 1 & & & 1 \\
\hline aac $\left(6^{\prime}\right)-1 b-a a r 3$ & & & 12 & 12 \\
\hline $\begin{array}{l}\text { aac }\left(6^{\prime}\right)-1 b \\
\text {-blaoxA-1-catB3-aar3 }\end{array}$ & 1 & & & 1 \\
\hline $\begin{array}{l}\text { dfrA1- aac }\left(6^{\prime}\right)-1 b \\
\text {-catB3-aar3 }\end{array}$ & & 1 & & 1 \\
\hline Total & 50 & 8 & 52 & $110^{c}$ \\
\hline
\end{tabular}

aClass 1 integrons for which only partial sequences of gene cassette arrays were amplified (IS26 detected in N0.47685 strain, dfrA14 detected in N0.45016 strain). ${ }^{b}$ Class 1 integrons for which PCR failed to amplify the gene cassette array. ${ }^{C} A$ total of 110 integrants were detected from 96 integron positive strains. * The gene cassette combination that our research group has previously reported.

$q n r C, 46$ isolates positive for $q n r D, 5$ isolates positive for $q n r S, 7$ isolates positive for oqxA and 45 isolates positive for aac $\left(6^{\prime}\right)-I b$, while all 153 isolates were negative for $o q x B$ and qepA. All aac $\left(6^{\prime}\right)-I b$ positive products were detected using nucleotide sequence analysis, and we found two types of the aac (6')-Ib gene, which were aac (6')-Ib (13/45) and aac (6')-Ib-cr (32/45). Statistical analysis of the drugsensitive phenotypes of the PMQR positive and negative groups showed that the PMQR positive group was significantly less sensitive to Ciprofloxacin $(21.8 \%$ vs. $65.2 \%, p<0.01)$ and Levofloxacin $(33.3 \%$ vs. $77.3 \%, p<0.01)$ than the PMQR negative group (Table 4).

\section{Relationships Between Various Promoters and Antibiotic Resistance Gene Load}

We compared the antibiotic resistance gene load of different promoters of 96 integron positive strains. We found that the relatively weak promoter $(\mathrm{PcH} 1)$ strains carried 6.88 resistance genes on average, of which 5.35 resistance genes were located in the integrons, and there were 1.53 resistance genes not located on the integrons (including: 1.12 beta-lactamase genes, 0.41 PMQR). The relatively strong promoter $\left(\mathrm{PcW}_{\mathrm{TGN}-10}\right.$ and $\left.\mathrm{PcS}\right)$ strains carried 3.57 and 3.88 resistance genes on average, respectively. Simultaneously, on average, 2.57 and 2.55 antibiotic resistant genes were located on integrons, while 1 (including: 0.85 beta-lactamase genes, 0.15 PMQR) and 1.3 (including: 0.9 beta-lactamase genes, 0.4 PMQR) antibiotic-resistant genes were not located on integrons, respectively (Table 5).

\section{DISCUSSION}

Integrons are genetic elements with a specific functional configuration that have evolved in bacteria and which can capture and express exogenous gene cassettes via site-specific recombination. In this study, 96 strains containing class 1 integrons were detected among 153 clinical isolates of Proteus, indicating that this evolutionary platform is common among clinical strains. Additionally, we detected 20 different gene cassettes, most of which conferred resistance to antibiotics. Antibiotics such as trimethoprim, chloramphenicol, and erythromycin were discovered in the early and mid-20th century and are now used extensively in clinical applications. However, during the process of bacterial evolution, antibiotic resistance gene cassettes have spread throughout clinical strains due to integration subsystems and high selection pressure imposed by the combined action of a large number of antibiotics, allowing the survival of bacteria carrying the appropriate antibiotic-resistance genes.

In contrast to previous research on Pc promoter polymorphisms in E. coli (Wei et al., 2013), the three promoters identified in the current study were relatively strong promoters (PcS, PcW $\mathrm{TGN}_{-10}$, and $\mathrm{PcH} 1$ ), with the stronger promoters (PcS, PcW $\mathrm{TGN}_{\mathrm{T}-10}$ ) accounting for $49 \%$ of all integron-positive strains. The variety of integron variable region gene cassettes was also shown to be more complicated, with est $X$ and $p s p$ being detected for the first time in clinical isolates of Proteus. Integrons usually spread between strains with the help of plasmids or transposons. Additionally, we detected the same array of gene cassettes in different phylogenetic groups of clinical isolates of Proteus, and the upstream promoters also remained stable. This may be due to the class 1 integrons being embedded in larger transposons or plasmids, or may be recombined in a conserved region of the class 1 integron $5 \mathrm{CS}$, such that the gene cassette array is combined with the same promoter.

This article reveals that strains with strong promoters have higher rates of antibiotic resistance than strains with weaker promoters, especially in amikacin, gentamicin, and tobramycin. This may be explained by the presence of a strong promoter in the variable region of the class 1 integron causing high expression of the relevant antibioticresistant genes. Interestingly, the antibiotic-resistant genotypes and phenotypes were highly matched among the seven strains with the strong promoter $\mathrm{PcW}_{\mathrm{TGN}-10}$, while strains containing other types of promoters do not show this phenomenon. In the phylogenetic analysis (Figure 3), we found that these 7 strains clearly belong to different colony 


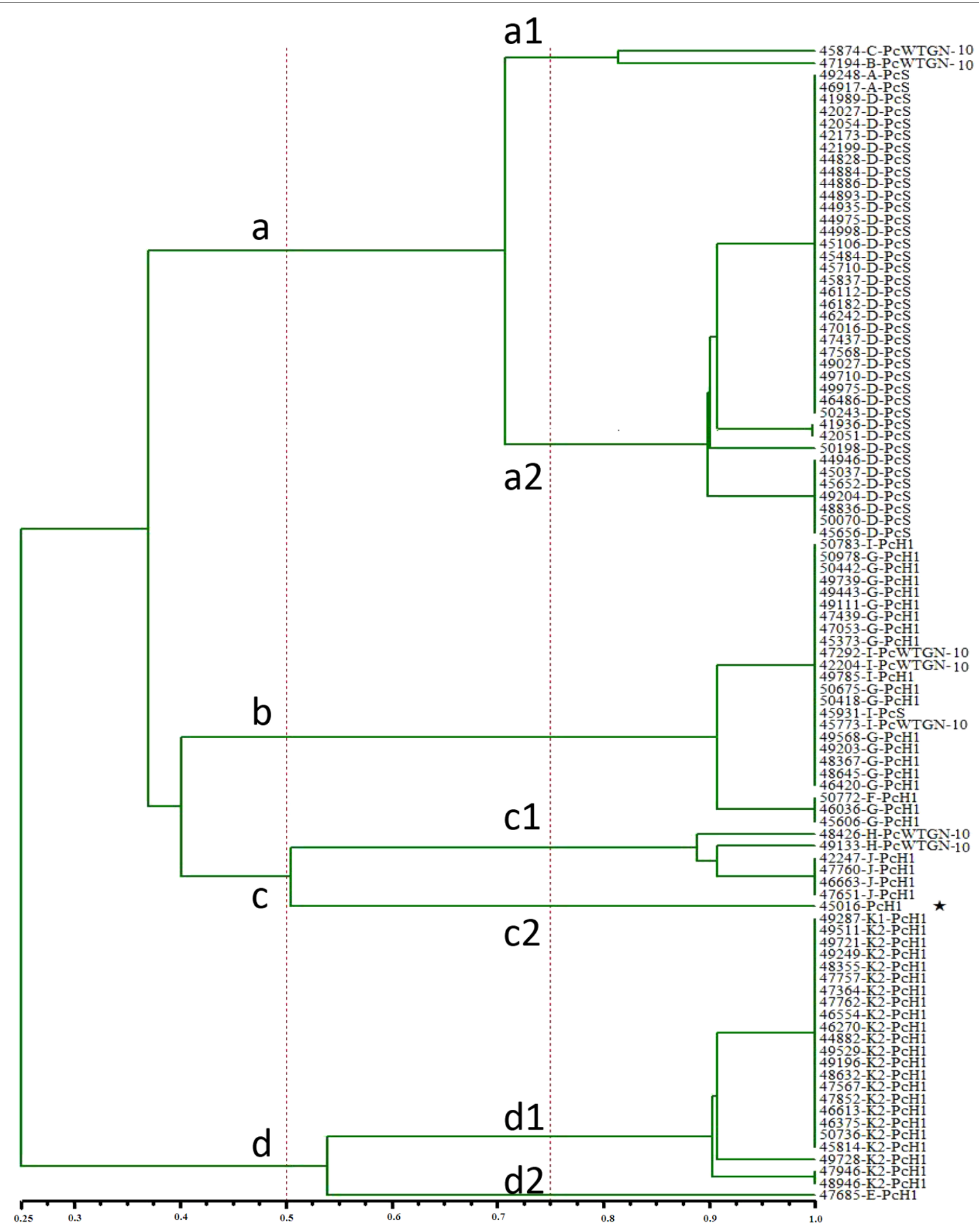

FIGURE 3 | Cluster analysis of 96 strains of Proteus based on ERIC-PCR. (50\% homology gathers as a main class, and $75 \%$ homology gathers into a subclass, $\star$ Class 1 integrons for which PCR failed to amplify the gene cassette array).

groups. In summary, antibiotic genes are located close to the promoter, making it relatively easy for the promoter to regulate their expression. However, the current results were only relevant to the individual strains studied, and clinical strains with different genetic backgrounds may present more complex phenomena. 
TABLE 3 | Associations of promoter variants with antibiotic-resistance phenotypes.

\begin{tabular}{|c|c|c|c|c|c|c|}
\hline \multirow[t]{2}{*}{ Promoter } & \multirow[t]{2}{*}{ Total no. of isolates } & \multicolumn{5}{|c|}{ No. $(\%)$ of isolates with resistance to ${ }^{a}$} \\
\hline & & AMK & GEN & TOB & SXT & $\mathrm{CHL}$ \\
\hline Total & 96 & $12(12.5)$ & $51(53.1)$ & 39 (40.6) & 69 (71.9) & $39(40.6)$ \\
\hline Strong promoter & 47 & $12(25.5)$ & 38 (82.8) & 37 (78.7) & $37(78.7)$ & $17(36.2)$ \\
\hline $\mathrm{PCW}_{T G N-10}$ & 7 & $1(14.3)$ & $5(71.4)$ & $5(71.4)$ & $6(85.7)$ & $1(14.3)$ \\
\hline PcS & 40 & $11(27.5)$ & 33 (85.2) & $32(80)$ & $31(77.5)$ & $16(40)$ \\
\hline $\mathrm{MIC}_{50}(\mu \mathrm{g} / \mathrm{ml})$ & & $\leq 2$ & $\geq 16$ & $\geq 16$ & $\geq 16$ & $\geq 64$ \\
\hline Weak promoter & 49 & $0(0)$ & $13(26.5)$ & $2(4.1)$ & $32(65.3)$ & $22(44.9)$ \\
\hline $\mathrm{PCH} 1$ & 49 & $0(0)$ & $13(26.5)$ & $2(4.1)$ & $32(65.3)$ & $22(44.9)$ \\
\hline $\mathrm{MIC}_{50}(\mu \mathrm{g} / \mathrm{ml})$ & & - & $\leq 4$ & $\leq 4$ & $\geq 16$ & 16 \\
\hline$p$-value ${ }^{b}$ & & 0.000 & 0.000 & 0.000 & 0.144 & 0.384 \\
\hline
\end{tabular}

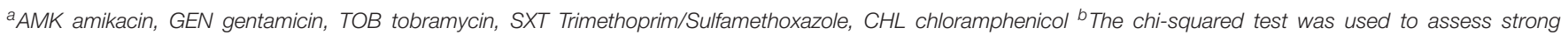
promoter and weak promoters.

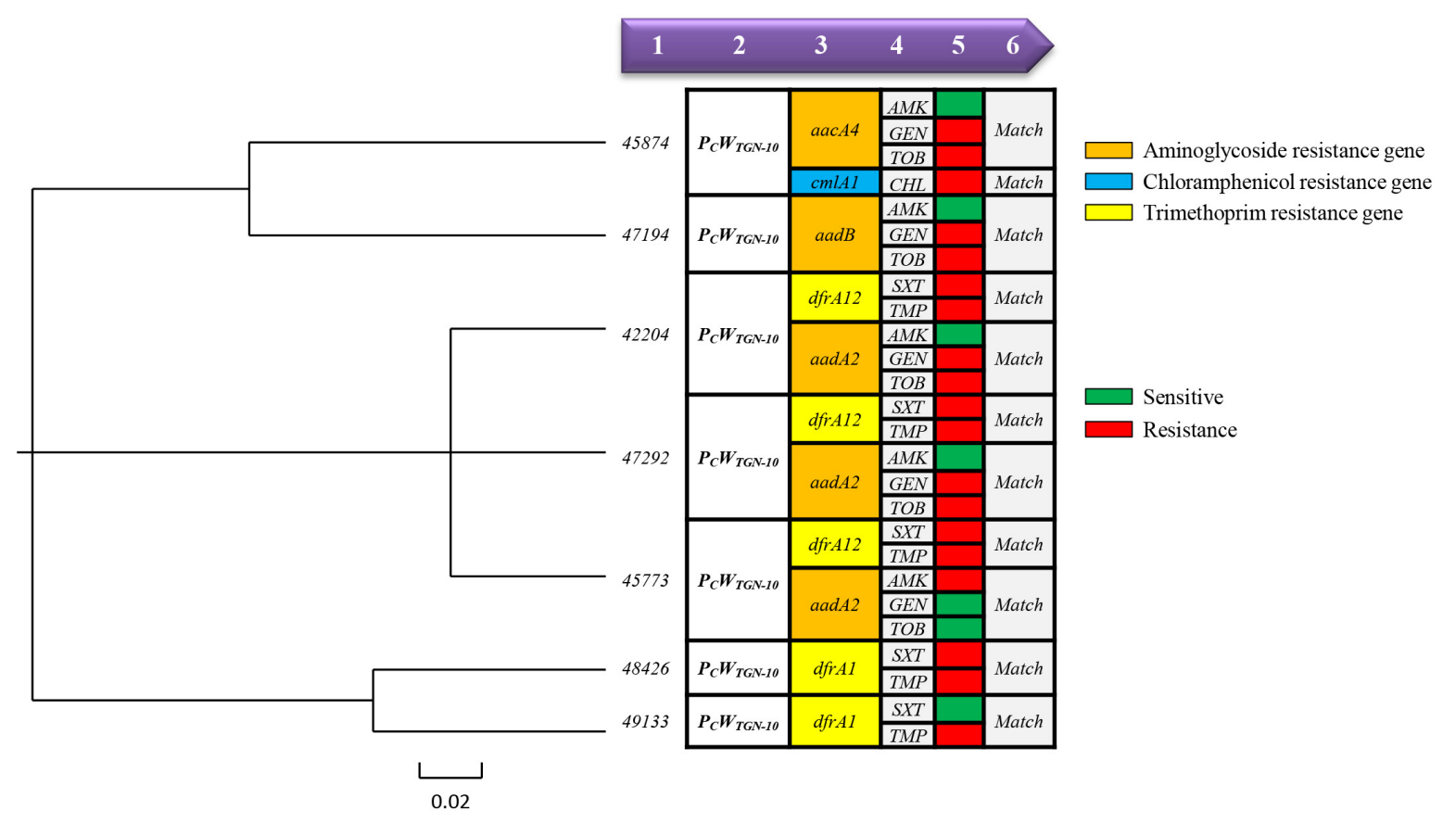

FIGURE 4 | Relationships between resistance gene and resistance phenotype in Proteus strains with strong promoters. (On the left side of this image is a phylogenetic tree based on the DNA sequence of each strain promoter using Vector NTI Advance 11 software, while the right side of this image shows the relationship between the variable region genotype and the resistant phenotype of each strain.) ${ }^{1}$ Strain number. ${ }^{2}$ Promoter type. ${ }^{3}$ Integron variable region genotype (aminoglycoside resistance gene shown in orange, chloramphenicol resistance gene shown in blue and trimethoprim resistance gene shown in yellow). ${ }^{4 a n d 5}$ Phenotype (sensitive shown in green, resistance shown in red). ${ }^{6}$ Indicates whether the genotype matches the resistant phenotype (at least one genotype corresponds to a resistant phenotype and is considered to be a "Match").

In this article, we elucidated the relationship between betalactamase genes and integrons that were carried in strains. Therefore, we screened the beta-lactamase resistance gene of 153 Proteus isolates, and found that the positive rate reached $45.8 \%$, which was significantly higher than previous reports (Ahn et al., 2017). A crucial argument shown by the statistical results is that there is a significant difference $(p<0.01)$ in the difference in drug resistance gene carrying between betalactamase genes and integrons in Proteus strains (Table 6).
As a result, we studied their impact on antibiotic resistance and attempted to explain the association between the antibiotic resistance genes carried by these strains and the integron promoter. Moreover, we found that beta-lactamase genes were significantly more detectable in ICUs and surgical wards than in other wards, as most ICU patients had severe disease, reduced immunity, and long-term use of antibiotics, all of which helped improve detection rate. For patients undergoing urologic surgery, the higher detection rate is related to its own physiological 
TABLE 4 | In vitro antimicrobial susceptibility of bla and PMQR.

\begin{tabular}{|c|c|c|c|c|c|c|}
\hline \multirow[t]{2}{*}{ Antimicrobial agent } & \multicolumn{3}{|c|}{ No. $(\%)$ of susceptible } & \multicolumn{3}{|c|}{ No. $(\%)$ of susceptible } \\
\hline & bla positive & bla negative & $p$-value & PMQR positive & PMQR negative & $p$-value \\
\hline & $N=70$ & $N=83$ & & $N=87$ & $N=66$ & \\
\hline Imipenem & $26(37.1)$ & $66(79.5)$ & 0.000 & $52(59.8)$ & $40(60.6)$ & 0.917 \\
\hline Meropenem & $25(35.7)$ & $60(72.3)$ & 0.000 & $55(63.2)$ & $40(60.6)$ & 0.742 \\
\hline Ciprofloxacin & $22(31.4)$ & $40(48.2)$ & 0.035 & $19(21.8)$ & $43(65.2)$ & 0.000 \\
\hline Levofloxacin & $33(47.1)$ & $47(56.6)$ & 0.242 & $29(33.3)$ & $51(77.3)$ & 0.000 \\
\hline Cefepime & 27 (38.6) & $70(84.3)$ & 0.000 & $57(65.5)$ & $40(60.6)$ & 0.532 \\
\hline Ceftriaxone & $25(35.7)$ & $64(77.1)$ & 0.000 & $57(65.5)$ & $32(48.5)$ & 0.034 \\
\hline Ceftazidime & $22(31.4)$ & $67(80.7)$ & 0.000 & $60(68.9)$ & $29(43.9)$ & 0.002 \\
\hline Cefazolin & $20(28.5)$ & $44(53.0)$ & 0.002 & $36(41.4)$ & $28(42.4)$ & 0.897 \\
\hline Aztreonam & $51(72.8)$ & 70 (84.3) & 0.082 & $73(83.9)$ & $48(72.7)$ & 0.092 \\
\hline Amikacin & $54(77.1)$ & $71(85.5)$ & 0.181 & $78(89.7)$ & $47(71.2)$ & 0.003 \\
\hline Gentamicin & $28(40.0)$ & $44(53.0)$ & 0.108 & $39(44.8)$ & $33(50.0)$ & 0.526 \\
\hline Tobramycin & $28(40.0)$ & $42(50.6)$ & 0.190 & $39(44.8)$ & $31(47.0)$ & 0.792 \\
\hline Sulfamethoxazole & $18(25.7)$ & $48(57.8)$ & 0.000 & $30(34.5)$ & $36(54.5)$ & 0.013 \\
\hline Chloramphenicol & $41(58.6)$ & $53(63.9)$ & 0.504 & $47(54.0)$ & $47(71.2)$ & 0.031 \\
\hline Piperacillin/Tazobactam & $70(100)$ & $83(100)$ & - & $87(100)$ & $66(100)$ & - \\
\hline Cefotetan & 70 (100) & 83 (100) & - & 87 (100) & 66 (100) & - \\
\hline
\end{tabular}

TABLE 5 | Associations of promoter variants with gene load.

\begin{tabular}{|c|c|c|c|c|c|c|c|}
\hline \multicolumn{2}{|c|}{ Promoter } & \multirow[t]{2}{*}{ Total no. of isolates } & \multicolumn{5}{|c|}{ No. of antibiotic resistance genes } \\
\hline & & & No. of genes & Located on integrons & Not located on integrons & bla & PMQR \\
\hline \multirow[t]{2}{*}{ "Strong" promoter } & PcW & 7 & $3.57^{a}$ & $2.57^{a}$ & $1^{a}$ & $0.85^{a}$ & $0.15^{a}$ \\
\hline & PcS & 40 & $3.85^{a}$ & $2.55^{a}$ & $1.3^{a}$ & $0.9^{a}$ & $0.4^{a}$ \\
\hline "Weak" promoter & $\mathrm{PcH} 1$ & 49 & $6.88^{a}$ & $5.35^{a}$ & $1.53^{a}$ & $1.12^{a}$ & $0.41^{a}$ \\
\hline
\end{tabular}

a Average value.

TABLE 6 | The relationship between carriage of integron and bla, PMQR.

\begin{tabular}{lccc}
\hline Genotypes & \multicolumn{2}{c}{ No.(\%) of carried } & $\boldsymbol{p}$-value \\
\cline { 2 - 3 } & Integron positive & Integron negative & \\
\hline & $\boldsymbol{N}=\mathbf{9 6}$ & $\boldsymbol{N}=\mathbf{5 7}$ & \\
bla & 57 & 13 & 0.000 \\
PMQR & 48 & 39 & 0.026 \\
\hline
\end{tabular}

structural characteristics, one of which is mainly urinary tract obstruction, which is conducive to bacterial reproduction, in addition to urinary catheterization, further increasing the chance of infection. Furthermore, we found that most beta-lactamase producing strains occur in the elderly or women. Among the strains studied, we did not find other significant differences in gene carriers. This may be due to the low immunity of the elderly and the vulnerability of the female urethra to infection, so that some strains or resistance genes can be transmitted horizontally.

TEM is the main type of $\beta$-lactamases, and the TEM-1 group is the most common. The CTX-M enzyme is a new group of plasmid-mediated beta-lactamase genes that have dominated in Europe, and have increased dramatically in many countries over the past decade (Mohd et al., 2019). Antibiotic consumption and different risk factors may also contribute to the current epidemiology of CTX-M enzymes in different geographic regions. In recent years, China has also presented an increasing trend, and there are few reports of beta-lactamase genes in Proteus isolated from Chinese hospitals. Interestingly, our research found that $b l a_{\mathrm{TEM}-1}, b l a_{\mathrm{OXA}-1}$, and bla $a_{\mathrm{CTX}-\mathrm{M}-14}$ were carried in the same strains, and they are resistant to third-generation cephalosporin, which may be synergy between them, increasing the ability of bacteria to hydrolyze cephalosporin. Drug susceptibility test data showed that Proteus producing beta-lactamase genes was significantly less sensitive to most third-generation cephalosporins (Table 4). If the patient is infected by a beta-lactamase producer, Cefotetan, Cefmetazole or Imipenem may be preferred prior to the results of the antibiotic susceptibility test, but if the patient is in a critical state, we should choose carbapenem antibiotics. These findings lead us to conclude that we should pay attention to the use of antibiotics in outpatient, inpatient and community hospitals, and reduce the chance of dissemination of $\beta$-lactamase gene levels due to antibiotic selection pressure. 
The PMQR genes discovered in recent years, such as qnrA, $q n r B, q n r C, q n r D$, qnrS, aac $\left(6^{\prime}\right)-I b-c r$, and $q e p A$ resistance genes, are an important mechanism for bacteria to resist quinolone. In this study, we explored the relationship between quinolone resistance genes and integrons in Proteus, and we also screened quinolone resistance genes in 153 Proteus isolates, with a positive rate of up to $56.9 \%$, mainly carrying $q n r D$ and $a a c\left(6^{\prime}\right)-I b$. Notably, $a a c\left(6^{\prime}\right)-I b$ is not resistant to quinolones, only variant $a a c\left(6^{\prime}\right)-I b-c r$ is resistant to quinolone. Among them, we studied $a a c\left(6^{\prime}\right)-I b$ in depth. The nucleic acid sequence of $a a c\left(6^{\prime}\right)-I b$ was found to contain Asp181Tyr (G541T) and Trp104Arg (T310C or T310A) in 32 strains of aac $\left(6^{\prime}\right)$-Ib (Hidalgo-Grass and Strahilevitz, 2010). The variant aac(6')-Ib-cr can confer bacterial resistance to Ciprofloxacin or Levofloxacin. In general, $a a c\left(6^{\prime}\right)-I b$ is mainly located in integrons and spreads horizontally with the spread of integrons. In this study, only 16 strains of $a a c\left(6^{\prime}\right)$-Ib were located in integrons $\left(a a c\left(6^{\prime}\right)\right.$-Ib-aar 3,12 ; $a a c\left(6^{\prime}\right)$ Ib-bla OXA-1-catB3-aar3,1; aac (6')-Ib-cmlA1,1; dfrA1-aac $\left(6^{\prime}\right)$-IbcatB3-aar3,1; aac $\left.\left(6^{\prime}\right)-I b-c m l A 1,1\right)$, and all aac $\left(6^{\prime}\right)-I b-c r$ variants were located on the integrons. However, $a a c\left(6^{\prime}\right)-I b$, which cannot confer PMQR, was carried by another 29 strains and may be located on other mobile elements, such as transposons or insertion sequences, although its specific mechanism of action needs further study. In the end, the experimental results were contrary to our hypothesis. There was no statistically significant difference in the quinolone resistance gene and integron carrying in the Proteus strains $(p>0.01)$ (Table 6).

In this study, multiple resistance genes were detected in isolates, and we also compared the antibiotic resistance "gene load" of strains with different promoters. As such, it further explains the fitness of the clinical bacteria. These results demonstrate that strains with relatively weak integron promoters can "afford" a heavier intra- and extra-integron antibiotic resistance gene load. Although many antibiotic resistance genes are not in the integrons, such as bla and PMQR, and are not directly related to the integron promoter, only a few representative bla and PMQR genes were investigated in this study, which have certain limitations. However, the drug resistance genes detected in this experiment also illustrates the principle of "gene load." Some studies have shown that the "super-integration antibiotic resistance gene load" may affect the fitness of pathogens, which is consistent with our research conclusions (Guo et al., 2012; Darmency et al., 2015).

\section{REFERENCES}

Ahn, J. Y., Ann, H. W., Jeon, Y., Ahn, M. Y., Oh, D. H., Kim, Y. C., et al. (2017). The impact of production of extended-spectrum $\beta$ lactamases on the 28-day mortality rate of patients with Proteus mirabilis bacteremia in Korea. BMC Infect. Dis. 17:327. doi: 10.1186/s12879-0172431-8

Brizio, A., Conceicao, T., Pimentel, M., Da, S. G., and Duarte, A. (2006). Highlevel expression of IMP-5 carbapenemase owing to point mutation in the -35 promoter region of class 1 integron among Pseudomonas aeruginosa clinical isolates. Int. J. Antimicrob. Agents 27, 27-31. doi: 10.1016/j.ijantimicag.2005. 08.023

\section{CONCLUSION}

In conclusion, to the best of our knowledge, this study provides the first evidence for polymorphisms within the variable region promoter of class 1 integrons in clinical Proteus isolates. The results indicated that the gene cassette in the integron in Proteus strains confers antibiotic resistance to aminoglycosides, trimethoprim, and chloramphenicol. Class 1 integron-positive Proteus strains generally have strong promoters, and strains with strong promoters are more resistant to amikacin, gentamicin, and tobramycin than strains with weaker promoters, strains with relatively weak integron promoters can "afford" a heavier intraand extra-integron antibiotic resistance gene load. Importantly, this study also provides the first evidence for the gene cassettes estX and psp in clinical isolates of Proteus. In addition, betalactamase genes and PMQR are widely prevalent in clinical isolates of Proteus, mainly blaTEM-1, blaOXA-1 and qnrD and aac $\left(6^{\prime}\right)$-Ib-cr. Interestingly, it was also found that in Proteus aac $\left(6^{\prime}\right)$-Ib-cr may be located on transposons, insertion sequences or other mobile genetic elements rather than on integrons, suggesting multiple pathways in its dissemination.

\section{AUTHOR CONTRIBUTIONS}

LX and QW conceived the study. WL coordinated the study. $\mathrm{XW}, \mathrm{NK}, \mathrm{MC}$, and LZ performed the experiments. LX and QW analyzed the data and wrote the manuscript. QW and WL revised the manuscript.

\section{FUNDING}

This study was supported by grants from Zhejiang Provincial Natural Science Foundation of China (Grant No. LY15H190006), the National Natural Science Foundation of China (Grant Nos. 81572034 and 81572061 ), and was partly supported by the Outstanding Academic Leaders Plan of Shanghai (Grant No. 2018BR07), the Shanghai Municipal Health and Family Planning Commission Youth Project (Grant No. 20164Y0156), and the Shanghai University of Medicine and Health Sciences Seed Foundation (Grant No. SFP-18-20-15-003), and Fengxian District Science and Technology Commission Youth Project (Grant No. 20181801).

Che, T., Bethel, C. R., Pusztai-Carey, M., Bonomo, R. A., and Carey, P. R. (2014). The different inhibition mechanisms of OXA-1 and OXA-24 $\beta$-lactamases are determined by the stability of active site carboxylated lysine. J. Biol. Chem. 289, 6152-6164. doi: 10.1074/jbc.M113.533562

Collis, C. M., and Hall, R. M. (2004). Comparison of the structure-activity relationships of the integron-associated recombination sites attI3 and attI1 reveals common features. Microbiology 150, 1591-1601. doi: 10.1099/mic.0. 26596-0

Collis, C. M., Kim, M. J., Stokes, H. W., and Hall, R. M. (1998). Binding of the purified integron DNA integrase Intll to integron- and cassette-associated recombination sites. Mol. Microbiol. 29, 477-490. doi: 10.1046/j.1365-2958. 1998.00936.x 
Collis, C. M., Kim, M. J., Stokes, H. W., and Hall, R. M. (2002). Integronencoded IntI integrases preferentially recognize the adjacent cognate attI site in recombination with a 59-be site. Mol. Microbiol. 46, 1415-1427. doi: 10.1046/j.1365-2958.2002.03260.x

Demarre, G., Frumerie, C., Gopaul, D. N., and Mazel, D. (2007). Identification of key structural determinants of the IntI1 integron integrase that influence attC x attI1 recombination efficiency. Nucleic Acids Res. 35, 6475-6489. doi: 10.1093/nar/gkm709

Darmency, H., Menchari, Y., Le Corre, V., and Délye, C. (2015). Fitness cost due to herbicide resistance may trigger genetic background evolution. Evolution 69, 271-278. doi: 10.1111/evo.12531

Frumerie, C., Ducos-Galand, M., Gopaul, D. N., and Mazel, D. (2010). The relaxed requirements of the integron cleavage site allow predictable changes in integron target specificity. Nucleic Acids Res. 38, 559-569. doi: 10.1093/nar/gkp990

Ghazi, I. M., Crandon, J. L., Lesho, E. P., McGann, P., and Nicolau, D. P. (2015). Efficacy of humanized high-dose meropenem, cefepime, and levofloxacin against Enterobacteriaceae isolates producing verona integronencoded metallo-beta-lactamase (VIM) in a murine thigh infection model. Antimicrob. Agents Chemother. 59, 7145-7147. doi: 10.1128/AAC.00794-15

Grieb, M. S., Nivina, A., Cheeseman, B. L., Hartmann, A., Mazel, D., and Schlierf, M. (2017). Dynamic stepwise opening of integron attC DNA hairpins by SSB prevents toxicity and ensures functionality. Nucleic Acids Res. 45, 10555-10563. doi: 10.1093/nar/gkx670

Guerin, E., Cambray, G., Sanchez-Alberola, N., Campoy, S., Erill, I., Da, R. S., et al. (2009). The SOS response controls integron recombination. Science 324:1034. doi: $10.1126 /$ science. 1172914

Guerin, E., Jove, T., Tabesse, A., Mazel, D., and Ploy, M. C. (2011). High-level gene cassette transcription prevents integrase expression in class 1 integrons. J. Bacteriol. 193, 5675-5682. doi: 10.1128/JB.05246-11

Guo, B., Abdelraouf, K., Ledesma, K. R., Nikolaou, M., and Tam, V. H. (2012). Predicting bacterial fitness cost associated with drug resistance. J. Antimicrob. Chemother. 67, 928-932. doi: 10.1093/jac/dkr560

Hidalgo-Grass, C., and Strahilevitz, J. (2010). High-resolution melt curve analysis for identification of single nucleotide mutations in the quinolone resistance gene aac $\left(6^{\prime}\right)$-Ib-cr. Antimicrob. Agents Chemother. 54, 3509-3511. doi: 10.1128/ AAC.00485-10

Jove, T., Da, R. S., Denis, F., Mazel, D., and Ploy, M. C. (2010). Inverse correlation between promoter strength and excision activity in class 1 integrons. PLoS Genet. 6:e1000793. doi: 10.1371/journal.pgen.1000793

Kim, J., Han, X., Bae, J., Chui, L., Louie, M., Finley, R., et al. (2016). Prevalence of plasmid-mediated quinolone resistance (PMQR) genes in nontyphoidal Salmonella strains with resistance and reduced susceptibility to fluoroquinolones from human clinical cases in Alberta, Canada, 2009-13. J. Antimicrob. Chemother. 71, 2988-2890. doi: 10.1093/jac/dkw232

Lévesque, C., Brassard, S., Lapointe, J., and Roy, P. H. (1994). Diversity and relative strength of tandem promoters for the antibiotic-resistance genes of several integron. Gene 142, 49-54. doi: 10.1016/0378-1119(94)90353-0

Lin, Q., Xu, P., Li, J., Huang, J., Chen, Y., and Deng, S. (2017). Study on the excision and integration mediated by class 1 integron in Streptococcus pneumoniae. Microb. Pathog. 111, 446-449. doi: 10.1016/j.micpath.2017.09.031

Loot, C., Ducos-Galand, M., Escudero, J. A., Bouvier, M., and Mazel, D. (2012). Replicative resolution of integron cassette insertion. Nucleic Acids Res. 40, 8361-8370. doi: 10.1093/nar/gks620

Makena, A., Duzgun, A. O., Brem, J., McDonough, M. A., Rydzik, A. M., Abboud, M. I., et al. (2015). Comparison of verona integron-borne metallo-betalactamase (VIM) variants reveals differences in stability and inhibition profiles. Antimicrob. Agents Chemother. 60, 1377-1384. doi: 10.1128/AAC.01768-15

Mohd, S. L. S., Wong, P. L., Sulaiman, H., Atiya, N., Shunmugam, R. H., and Liew, S. M. (2019). Clinical prediction models for ESBL-Enterobacteriaceae colonization or infection: a systematic review. J. Hosp. Infect. S01956701(19)30014-3. doi: 10.1016/j.jhin.2019.01.012

Moura, A., Jove, T., Ploy, M. C., Henriques, I., and Correia, A. (2012). Diversity of gene cassette promoters in class 1 integrons from wastewater environments. Appl. Environ. Microb. 78, 5413-5416. doi: 10.1128/AEM.00042-12
Moyo, S., Haldorsen, B., Aboud, S., Blomberg, B., Maselle, S. Y., Sundsfjord, A., et al. (2015). Identification of VIM-2-producing Pseudomonas aeruginosa from tanzania is associated with sequence types 244 and 640 and the location of blaVIM-2 in a TniC integron. Antimicrob. Agents Chemother. 59, 682-685. doi: 10.1128/AAC.01436-13

Nivina, A., Escudero, J. A., Vit, C., Mazel, D., and Loot, C. (2016). Efficiency of integron cassette insertion in correct orientation is ensured by the interplay of the three unpaired features of attC recombination sites. Nucleic Acids Res. 44, 7792-7803. doi: $10.1093 /$ nar/gkw646

Papagiannitsis, C. C., Tzouvelekis, L. S., and Miriagou, V. (2009). Relative strengths of the class 1 integron promoter hybrid 2 and the combinations of strong and hybrid 1 with an active p2 promoter. Antimicrob. Agents Chemother. 53, 277-280. doi: 10.1128/AAC.00912-08

Rzeczkowska, M., Piekarska, K., and Gierczyński, R. (2012). Characteristic of fluoroquinolone resistant clinical isolates of $K$. pneumoniae, P. mirabilis and E. coli producing ESBL and AmpC $\beta$-lactamases. Med. Dosw. Mikrobiol. 64, 285-295.

Subedi, D., Vijay, A. K., Kohli, G. S., Rice, S. A., and Willcox, M. (2018). Nucleotide sequence analysis of NPS-1 $\beta$-lactamase and a novel integron (In1427)-carrying transposon in an MDR Pseudomonas aeruginosa keratitis strain. J. Antimicrob. Chemother. 73, 1724-1726. doi: 10.1093/jac/dky073

Sunde, M. (2005). Class I integron with a group II intron detected in an Escherichia coli strain from a free-range reindeer. Antimicrob. Agents Chemother. 49, 2512-2514. doi: 10.1128/AAC.49.6.2512-2514.2005

Tsai, H. C., Chou, M. Y., Wu, C. C., Wan, M. T., Kuo, Y. J., Chen, J. S., et al. (2018). Seasonal distribution and genotyping of antibiotic resistant strains of listeriainnocua isolated from a river basin categorized by ERIC-PCR. Int. J. Environ. Res. Public Health 15:E1559. doi: 10.3390/ijerph15071559

Velasova, M., Smith, R. P., Lemma, F., Horton, R. A., Duggett, N., Evans, J., et al. (2019). Detection of extended spectrum $\beta$-Lactam (ESBL), AmpC and carbapenem resistance in enterobacteriaceae in beef cattle in Great Britain in 2015. J. Appl. Microbiol. 126, 1081-1095. doi: 10.1111/jam.14211

Vinue, L., Jove, T., Torres, C., and Ploy, M. C. (2011). Diversity of class 1 integron gene cassette Pc promoter variants in clinical Escherichia coli strains and description of a new P2 promoter variant. Int. J. Antimicrob. Agents 38, 526-529. doi: 10.1016/j.ijantimicag.2011.07.007

Wei, Q., Hu, Q., Li, S., Lu, H., Chen, G., Shen, B., et al. (2014). A novel functional class 2 integron in clinical Proteus mirabilis isolates. J. Antimicrob. Chemother. 69, 973-976. doi: 10.1093/jac/dkt456

Wei, Q., Jiang, X., Li, M., Chen, X., Li, G., Li, R., et al. (2011). Transcription of integron-harboured gene cassette impacts integration efficiency in class 1 integron. Mol. Microbiol. 80, 1326-1336. doi: 10.1111/j.1365-2958.2011.07648.x

Wei, Q., Jiang, X., Li, M., Li, G., Hu, Q., Lu, H., et al. (2013). Diversity of gene cassette promoter variants of class 1 integrons in uropathogenic Escherichia coli. Curr. Microbiol. 67, 543-549. doi: 10.1007/s00284-013-0399-1

Wilson, L. A., and Sharp, P. M. (2006). Enterobacterial repetitive intergenic consensus (ERIC) sequences in Escherichia coli: evolution and implications for ERIC-PCR. Mol. Biol. Evol. 23, 1156-1168. doi: 10.1093/molbev/msj125

Wong, M. H., Chan, E. W., Liu, L. Z., and Chen, S. (2014). PMQR genes oqxAB and $a a c\left(6^{\prime}\right) I b-c r$ accelerate the development of fluoroquinolone resistance in Salmonella typhimurium. Front. Microbiol. 5:521. doi: 10.3389/fmicb.2014. 00521

Conflict of Interest Statement: The authors declare that the research was conducted in the absence of any commercial or financial relationships that could be construed as a potential conflict of interest.

Copyright (c) 2019 Xiao, Wang, Kong, Cao, Zhang, Wei and Liu. This is an openaccess article distributed under the terms of the Creative Commons Attribution License (CC BY). The use, distribution or reproduction in other forums is permitted, provided the original author(s) and the copyright owner(s) are credited and that the original publication in this journal is cited, in accordance with accepted academic practice. No use, distribution or reproduction is permitted which does not comply with these terms. 